\title{
GEORGE SAND NO BRASIL
}

\section{GEORGE SAND IN BRAZIL}

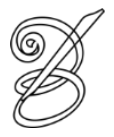 \\ Patrícia Rodrigues Costa ${ }^{1}$ \\ Doutoranda em Estudos da Tradução (PGET/UFSC) \\ Florianópolis, Santa Catarina, Brasil \\ prcosta1986@gmail.com \\ Germana Henriques Pereira de Sousa ${ }^{2}$ \\ POSTRAD/UnB \\ Brasília, Distrito Federal, Brasil \\ germanah@gmail.com
}

Resumo: Trata-se de apresentar o levantamento das obras traduzidas e publicadas da escritora francesa George Sand no Brasil, desde sua primeira publicação em 1841 até 2013.

Palavras-chave: George Sand; Literatura francesa; Tradução literária; História da tradução no Brasil.

Abstract: This essay lists George Sand's translated and published works in Brazil since 1841 to 2013.

Keywords: George Sand; French literature; Literary translation; History of translation in Brazil.

\section{Amantine-Aurore-Lucile Dupin ou George Sand}

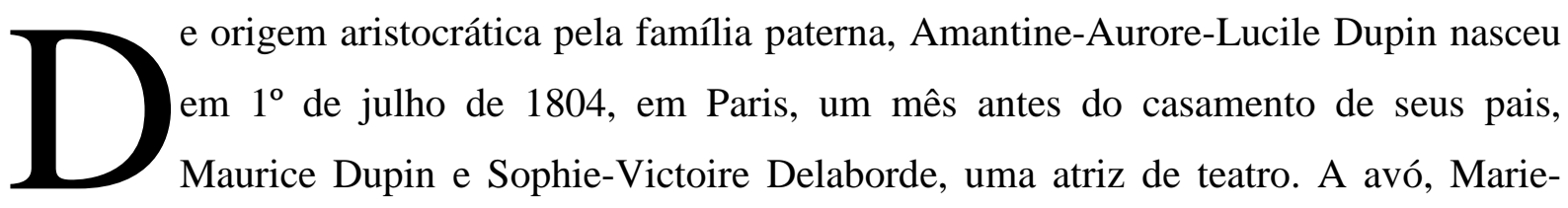
Aurore de Saxe, após o casamento, Marie-Aurore Dupin, era filha do marechal Maurice de Saxe, o Conde de Saxe. Seu tataravô Frédéric-Auguste foi rei da Polônia. Todas as mulheres da família foram batizadas como Aurore, em homenagem da tataravó de Sand, Aurore de Koenigsmark.

No outono de 1805, teve início as guerras napoleônicas. Maurice Dupin, pai da escritora, partiu para a guerra junto com o príncipe Murat. Em 8 setembro de 1808, com apenas três meses de idade, morre Auguste, irmão de Amantine, que era cego, e uma semana depois, Maurice morre acidentalmente após uma queda de cavalo. 
Após a morte de seu pai, a guarda de Amantine foi disputada entre sua mãe e sua avó Mme. Dupin de Francueil. Amantine acabou sendo criada por sua avó em Nohant. JeanFrançois Deschartres, instrutor de Maurice Dupin, tornou-se responsável pela educação da garotinha. Deschartres vestia Amantine, quando criança, com roupas masculinas para que pudesse correr pelos campos e caçar. Quando adolescente, Amantine estudou em Paris dança, escrita e desenho. Apreciava também a literatura e a música. Devido às intensas discussões com sua avó, que se considerava deísta e rejeitava todos os dogmas e formas de religião, Amantine foi internada, aos 14 anos, em 12 de janeiro de 1818, no convento das Dames augustines anglaises, em Paris, no qual permaneceu por dois anos antes de retornar a Nohant,

258 onde estudou inglês e italiano.

Em 26 de dezembro de 1821, morre Mme. Dupin de Francueil, deixando consignado em seu testamento o desejo de que René Vallet de Villeneuve, seu primo, se tornasse o tutor de Amantine. Porém, sua mãe, Sophie-Victorie, que era extremamente católica, se opõe a tal desejo e retorna a Paris com Amantine, não permitindo que ela praticasse a leitura ou possuísse qualquer livro, o que tornou a vida das duas insustentável.

Na primavera de 1822, Amantine e Sophie-Victorie foram visitar James e Angèle Roëttiers, em Plessis-Picard, e acabaram lá permanecendo por cinco meses, período em que James convenceu Sophie a lhe confiar Amantine. Em 19 de abril de 1822, Amantine conhece Jean-François Dudevant, mais conhecido como Casimir Dudevant ${ }^{3}$, homem de pouca educação, com o qual se casou em 17 de setembro de 1822. No ano seguinte, teve seu primeiro filho, Maurice. Amantine começou a escrever a partir de 1831, ano em que começa a utilizar por pseudônimo G. Sand e, posteriormente, George Sand.

\subsection{Amantine e seus amantes}

A escritora George Sand é reputada por ter vivido intensamente os relacionamentros amorosos. Vários desses encontros amorosos foram vividos com outros escritores ou pessoas ligadas ao meio artístico. É de um deles que adveio o codinome Sand, como veremos adiante.

Em 1825, então jovem Amantine conhece Aurélien de Sèze, um advogado, que se tornou seu amante por cinco anos. Em 1827, Amantine se reencontra com Stéphane Ajasson de Grandsagne ${ }^{4}$, médico e tradutor de autores latinos, que segundo consta é o pai ${ }^{5}$ de Solange, sua filha. Em 1831, Amantine conhece, em Paris, Jules Sandeau, que se torna seu amante até 1833, mas também parceiro na escrita ${ }^{6}$ dos romances Le Commissionnaire, e Rose et Blanche, publicados sob o pseudônimo de J. Sand, em dezembro de 1831. Este último foi escrito pela 
dupla em parceria com Balzac. Em 18 de maio de 1832, a escritora francesa, mais conhecida à época como Aurore Dudevant, publica seu famoso livro Indiana sob o pseudônimo de G. Sand. Em 1833, com a publicação de Lélia, George Sand se torna uma autora da moda e, devido ao seu sucesso, acaba assinando um contrato de exclusividade com a Revue des Deux Mondes. Em 1833, Sand se apaixona ${ }^{7}$ por Marie Dorval ${ }^{8}$, uma das mais prestigiadas atrizes francesas do século XIX, com quem teve um relacionamento.

Em junho de 1833, George Sand se encontra com Alfred de Musset em um jantar. Em 25 de julho de 1833, após Musset ter lido Lélia, eles se reencontram e Musset ${ }^{9}$ declara seu amor a Sand. Em 1834, em Veneza, Musset cai doente, e o médico Pietro Pagello, que tratou do escritor, acaba se tornando amante de Sand. Com o retorno de Musset à França, Sand, em situação financeira difícil, decide permanecer em Veneza, período em que escreve para a Revue des Deux Mondes os seguintes títulos: Le Secrétaire intime (1834), Jacques (1834), Leone Leoni (1835) e os primeiros capítulos de Lettres d'un voyageur (1834 - 1837).

Em agosto de 1835, Sand retorna a Paris com Pagello. Devido aos ciúmes gerados pelo estreito contato de Sand com Musset, Pagello retorna a Veneza. Musset e Sand voltam a ser amantes, mas se separam pouco tempo depois. Após esse término, Sand não consegue mais escrever e, num ato extremo, corta seu cabelo e o envia a Musset. Por causa das idas e vindas desse relacionamento, Sand se cansa e foge para Nohant, em 6 de março de 1835. Um mês depois, Sand conhece o célebre advogado Michel de Bourges, também casado, e que, após ler Lélia, apaixona-se por Sand. Por meio desse relacionamento, Sand é apresentada à política e torna-se republicana. Em 1836, Sand se divorcia de Casimir, com quem ainda era casada, apesar da movimentada vida sexual. O relacionamento com Bourges termina em 1837. Em seguida, ela teve como amantes o escritor Charles Didier e também Félicien Mallefille, instrutor de seu filho Maurice.

Em junho de 1838, Sand reencontra Frédéric Chopin ${ }^{10}$, com quem mantém um affair até 11 de novembro de 1846. Em 1849, conhece o dramaturgo Alexandre Manceau, amigo de Maurice, com quem se relacionou até 1865, ano da morte de Manceau. Este foi seu último amante $^{11}$.

\section{A escritora George Sand}

George Sand escreveu de forma contínua entre 1830 e 1876 diversos gêneros literários: romances campestres, socialistas e sentimentais, contos, peças de teatro, artigos críticos publicados em jornais e ensaios políticos, textos autobiográficos e diversas 
correspondências. A escrita de Sand é um marco na história do romantismo francês, sendo referência em relação aos direitos da mulher, especialmente no tocante ao prazer, e à igualdade de direitos com relação aos homens.

Em 1831, a jovem Amantine viaja a Paris e mantém um círculo de amizades que incluía artistas, intelectuais e políticos. Em meio a esse círculo, Amantine conhece Jules Sandeau, também um escritor iniciante. Para compor seu pseudônimo, usou parte do nome do amante, a fim de possibilitar a publicação e maior circulação de seus textos, além de proteger a si mesma e a suas obras contra o preconceito em relação a uma escrita feminina.

A partir de 1832, com a publicação de Indiana, seu primeiro romance de autoria 260 individual, um sucesso de público, Amantine passa a utilizar o pseudônimo George Sand. Além de utilizar um pseudônimo masculino, George Sand vestia-se com trajes masculinos para poder participar de atividades, à época, consideradas apanágio dos homens, como, por exemplo, as reuniões literárias. “George Sand foi uma das primeiras mulheres escritoras do seu tempo, a publicar uma obra autobiográfica” (MACIEL, 2011, p. 78), com a publicação de Histoire de ma vie publicado entre 1854 e 1855. Contudo, foi a partir da publicação de Lélia que Sand distinguiu sua escrita literária, tornando-se uma autora reconhecida em território nacional e internacional. As traduções, obviamente, sedimentaram sua fama fora da França.

\section{Traduções de George Sand no Brasil}

De modo a tentar compreender uma das possíveis vias de entrada de George Sand no Brasil, foi necessário pesquisar também suas primeiras traduções em Portugal. Assim, após pesquisa na PORBASE - Base Nacional de Dados Bibliográficos ${ }^{12}$ de Portugal, encontramos a publicação da tradução em Portugal da obra “Consuelo”, pela editora Typ. de J. de Castro \& Irmão em 1845 e que foi publicada originalmente em 1843 com o mesmo título. Contudo, acreditamos que os textos de Sand tenham circulado em formato de folhetim em terras portuguesas, uma vez que a imprensa em Portugal data de 1834 e, assim como na França, teve intensa publicação de romances-folhetim (RAFAEL, 2012, p. 32), o que pode nos indicar a possibilidade da circulação antes de 1845 de obras de George Sand em Portugal.

As primeiras traduções para o português de George Sand, publicadas no Brasil, datam do século XIX, algumas delas pouco tempo após serem publicadas na França em formato de livro ou em folhetim. De acordo com Müller (2011), em razão da existência do romancefolhetim, houve no século XIX o aumento da circulação de romances estrangeiros no Brasil 
tanto em língua original quanto em tradução. Em relação às traduções deve-se pontuar que muito do que circulava em português no Brasil ainda era originário de Portugal, contudo

\begin{abstract}
Em meados do Oitocentos, já havia por aqui tradutores que se dedicavam profissionalmente à atividade, geralmente contratados pelos jornais para traduzir folhetins. Nomes como Caetano Lopes de Moura, José Alves Visconti Coaracy, Francisco de Paula Brito, Justiniano José da Rocha e Antonio José Fernandes dos Reis foram responsáveis por um expressivo número de traduções de romances de sucesso na época, principalmente os de maior apelo popular [...], grande parte dos quais de origem francesa. Traduzidos ou no idioma de origem, o fato é que, em meados do século XIX, os romances franceses pareciam estar por toda parte. (MÜLLER, 2011, p. 67)
\end{abstract}

Assim,

\begin{abstract}
Não se pode esquecer, quando se trata da presença do romance francês no Brasil oitocentista, que, ao lado dos folhetins de sucesso desprezados pelas histórias literárias do século $\mathrm{XX}$, também circulavam por aqui obras de autores hoje considerados clássicos da literatura francesa, como Chateaubriand, Hugo, Vigny, George Sand e Balzac; os dois últimos, aliás, muito presentes nos anúncios de livrarias. (MÜLLER, 2011, p. 69)
\end{abstract}

Destacamos ainda que Dom Pedro II, um dos leitores de Sand, com que mantinha contato durante a viagem à Europa, em 1871 - 1872, foi censurado pela Princesa Isabel, pois, segundo ela, D. Pedro como “um bom católico” deveria se afastar do que fosse “imoral”, já que Sand era uma feminista da primeira safra (FERNANDES, 2012).

De acordo com Ilana Heineberg (2004b, p. 63), George Sand foi publicada no Brasil pela primeira vez em 1841, no Jornal do Commercio, com a tradução da obra L'Uscoque (1838), em português “O pirata”. Como folhetim (HEINEBERG, 2004b), foram publicadas as seguintes traduções: “Mont Reveche” (1853-1854), no original Mont-Revêche, 1853; “A derradeira Adini” (1853 - 1854), no original La dernière Aldini, 1839; “O homem de gelo" (1858), no original L'homme de neige, 1859; “O Marquês de Villemer” (1862), no original Le Marquis de Villemer, 1861; “Mademoiselle Marquem” (1868), no original Mademoiselle Merquem, 1868 (cf.Tabela 1). Vale destacar que com relação ao "O Marquês de Villemer” (1862), possivelmente trata-se da publicação de uma tradução portuguesa publicada em Lisboa pela Livraria Editora Guimarães ${ }^{13}$.

“O homem de gelo” foi publicado em livro apenas em 1859, tendo sido publicado em 1858 como folhetim na Revue des Deux Mondes. As obras de George Sand provavelmente circularam em francês em território brasileiro, já que a Revue des Deux Mondes tinha circulação no Brasil (FERNANDES, 2012, p. 71) e a autora tinha contrato de exclusividade ${ }^{14}$ 
com essa revista após ter sido apresentada em 1833 seu editor, François Buloz, e ter se tornado uma autora conhecida depois da publicação independente de "Indiana” (1832) e “Lélia” (1833). Destacamos também que nas obras “A derradeira Adini” e “O homem de gelo” o nome de George Sand foi grafado como Jorge Sand.

As obras traduzidas publicadas no século XIX, no Brasil, em sua maioria, não mencionam o tradutor. Contudo, mesmo sabendo que possivelmente se tratem traduções portuguesas, publicadas por folhetins brasileiros, e não de traduções brasileiras, vamos apresentá-las no levantamento realizado para ilustrar a entrada das obras de Sand aqui no Brasil. Das 10 publicações no período de 1841 a 1888, temos duas traduções portuguesas: “O 262 homem de gelo” (L'homme de neige, 1859), traduzido por Júlio de Magalhães (Lisboa: Typ. da Empreza Serões Românticos), e “O diabo no campo - volume 2” (Le Diable au champs, 1856), traduzido por Pedro dos Reys (Lisboa: Ed. David Corazzi). Além disso, a tradução “A derradeira Adini” (La dernière Aldini, 1839), publicada em folhetim entre 1853 e 1854, no Correio Mercantil, tem por tradutor Dr. Cardoso de Menezes, provavelmente João Cardoso de Meneses e Sousa, Barão de Paranapiacaba, um colaborador do Correio Mercantil que traduzia dos seguintes idiomas: inglês, francês, italiano, grego, latim e hebraico.

Publicada em 1861, a obra Le Marquis de Villemer teve três traduções para o português em formato de livro, além da tradução em folhetim datada de 1862, intituladas por “A Dama de Companhia” publicada pela editora Casa Mandarino, “A Dama de Companhia”, pela editora Ed. Getulio M. Costa e “Ama de companhia - o Marquês de Villemer”, pela Editora Aurora, todas sem informações relativas às datas de publicação e aos seus tradutores. Porém, podemos inferir, por meio de outras publicações realizadas em formato de bolso na “Coleção Azul”, da Editora Aurora, que a tradução intitulada “Ama de companhia” data da década de 1940 (Tabela 2).

Publicada na França em 1849, La Petite Fadette teria, em princípio, seis traduções publicadas no Brasil (Tabela 3). “Em princípio”, uma vez que o tradutor José Maria Machado teria feito duas traduções da mesma obra para editoras diferentes (Edigraf, $19-{ }^{15}$ e Clube do Livro, 1957). Sobre esse fato, recordamos o destacado pela tradutora Denise Bottmann com relação às “traduções especiais” do Clube do Livro ${ }^{16}$. Tais traduções contam como sendo de autoria de José Maria Machado ${ }^{17}$, o tradutor mais assíduo daquela editora, mas, possivelmente, tratam-se de adaptações de traduções portuguesas e não de traduções de sua própria autoria. Além desses títulos, a Abril Editora teria publicado duas traduções de "A pequena Fadette”, uma em 1972 e outra em 1973. A tradução de La Petite Fadette realizada 
por Augusto de Sousa foi intitulada “Os Gêmeos” (1953). A escolha pelo título "Os gêmeos” em vez de “A pequena Fadette” provavelmente se deu pelo fato de essa obra ter sido publicada em 1905 pela editora London Blackie ${ }^{18}$ sob o título de Les Jumeaux. Augusto de Sousa também foi o tradutor de todas as obras de Alexandre Dumas publicadas na Coleção Saraiva (GUIMARÃES, 2008, p. 89).

Publicada em 1859, a obra Elle et lui foi inspirada na relação de Sand com Alfred de Musset e teve três traduções no Brasil, a primeira datada de 1943 e as outras duas de 1959. A respeito da primeira tradução intitulada "Ela e Ele”, de 1943, vale ressaltar que não encontramos informações acerca do tradutor. As traduções de 1959, "Ela e Ele” e "Almas Inquietas” foram feitas por José Maria Machado (Tabela 4). Com relação à “Almas Inquietas”, a princípio não sabíamos, por meio do título, que se tratava da obra Elle et lui. Ao pesquisarmos qual seria seu original, verificamos que não havia na obra de Sand um título que constituísse um equivalente direto em francês. Por esse motivo, pesquisamos a disponibilidade da tradução na Internet, obtendo como resultado duas bibliotecas, na Universidade de Brasília e na Associação Educacional Dom Bosco (AEDB), que disponibilizam a tradução “Almas Inquietas”. Após contactar a AEDB, pedindo maiores informações sobre o livro “Almas Inquietas”. O bibliotecário Marcos Santos ${ }^{19}$ nos respondeu enviando em anexo ao e-mail as imagens escaneadas da capa, folha de rosto, nota explicativa e a primeira página do primeiro capítulo, de modo que pudemos verificar que "Almas inquietas” nada mais era do que a obra Elle et Lui vertida para o português do Brasil.

Em suma, há “duas traduções” de Elle et Lui realizadas no mesmo ano pelo mesmo tradutor, José Maria Machado, e intituladas como “Almas Inquietas” e “Ela e Ele”. Deve-se ressaltar a possibilidade das traduções realizadas por José Maria Machada, “Almas inquietas” e "Ela e ele”, serem uma adaptação da tradução portuguesa realizada por Óscar Sidónio e intitulada “Almas imperfeitas”20, publicada em 1945.

A obra autobiográfica "Histoire de ma vie" começou a ser escrita por Sand em abril de 1847 e foi publicada em formato de folhetim no La Presse a partir 17 de agosto de 1854 a 17 de agosto de $1855^{21}$ (Tabela 5). “História da minha vida” foi traduzida por Gulnara Lobato de Morais Pereira, escritora e tradutora, sobrinha e nora de Monteiro Lobato. A tradução foi lançada entre 1945 e 1947 quase um século após a publicação do original, em cinco volumes, assim como no original.

Dentre as obras com somente uma tradução no Brasil - "Indiana”, 1843 (Indiana, 1832), “Valentina”, 1937 (Valentine, 1832), “Mauprat”, 1945 (Mauprat, 1837), “Jeanne”, 
1943 (Jeanne, 1844), “Narciso”, 1942 (Narcisse, 1859), “O último amor”, 1952 (Le dernier amour, 1867), dedicado a Gustave Flaubert (Tabela 6) - destacamos Indiana, primeiro romance publicado sob o pseudônimo de G. Sand e também seu primeiro romance feminista no qual destaca a injustiça que as mulheres sofriamm no casamento, na família e na sociedade. O romance Indiana faz diversas alusões ao conto filosófico do século XVIII de Bernadin de Saint-Pierre, La chaumière indienne (1791), bem como ao romance Paul et Virginie (1789), do mesmo autor (IPPOLITO, 2009).

Valentine tematiza o casamento e a educação recebida pelas mulheres na França do século XIX. Foi publicado somente três meses após Indiana, e traduzido no Brasil pouco mais 264 de um século depois de sua publicação original. Almir de Andrade, tradutor de Indiana e Mauprat, romance histórico-socialista, foi também tradutor do Quixote (COBELO, 2010).

La mare au diable, romance campestre publicado em 1846 e um dos mais importantes de George Sand, tem três traduções no Brasil (Tabela 7). A primeira, “O pântano do diabo”, datada de 1938, foi traduzida por Adonias Filho (MATTOS, 2011, p. 7), imortal da Academia Brasileira de Letras. Em 1952, a segunda tradução foi realizada por José Maria Machado e intitulada O charco do diabo. A terceira tradução, “O pântano do diabo” (1963), foi realizada por Maria Tostes Regis, que também traduziu Dom Quixote de la Mancha para a editora Itatiaia. Assim, somente 42 anos após a última tradução do século XX houve nova publicação de traduções das obras de George Sand, isto é, no século XXI.

No século XXI, três foram as traduções de textos de George Sand nunca traduzidos no Brasil (Tabela 8): Spiridion (1839), traduzido por Milton Hatoum como “Espiridião” (2005); Histoire du véritable Gribouille (1850), conto escrito para sua afilhada Nancy, filha de Alphonse Fleury, traduzido por Cláudio Giordano como "História do verdadeiro Simplício” (2013) e Le chêne parlant por Dorothée de Bruchard como “O carvalho falante” (2013), que originalmente faz parte dos Contes d'une Grand-mère (1873 - 1876) escritos para seus netos Aurore e Gabrielle ${ }^{22}$. 
Tabela 1. Publicações de obras traduzidas de George Sand no século XIX

\begin{tabular}{|c|c|c|c|c|c|c|c|}
\hline & $\begin{array}{l}\text { Título da } \\
\text { tradução }\end{array}$ & Tradutor(a) & $\begin{array}{c}\text { Ano de } \\
\text { publicação }\end{array}$ & Editora & Fontes & Título do Original & $\begin{array}{c}\text { Ano de } \\
\text { Publicação }\end{array}$ \\
\hline 1. & O pirata & - & 1841 & Jornal do commercio & $\begin{array}{c}\text { (HEINEBERG, 2004b, } \\
\text { p. 63) }\end{array}$ & L'Uscoque & 1838 \\
\hline 2. & O pirata & - & 1841 & $\begin{array}{l}\text { Typ. Imp. e Const. } \\
\text { de J. Villeneuve e } \\
\text { Companhia } \\
\end{array}$ & $\begin{array}{c}\text { (FERNANDES, 2012, } \\
\text { p. 76) }\end{array}$ & L'Uscoque & 1838 \\
\hline 3. & $\begin{array}{l}\text { A derradeira } \\
\text { Adini (Jorge } \\
\text { Sand) } \\
\end{array}$ & $\begin{array}{l}\text { Dr. Cardoso de } \\
\text { Menezes }\end{array}$ & 1853-1854 & Correio Mercantil & $\begin{array}{c}\text { (HEINEBERG, 2004b, } \\
\text { p. 63) }\end{array}$ & La dernière Aldini & 1839 \\
\hline 4. & Mont Reveche & & $1853 / 1854$ & $\begin{array}{l}\text { Diário do Rio de } \\
\text { Janeiro }\end{array}$ & $\begin{array}{c}\text { (HEINEBERG, 2004b, } \\
\text { p. 63) }\end{array}$ & Mont-Revêche & 1853 \\
\hline 5. & $\begin{array}{c}\text { O Homem de } \\
\text { Gelo (Jorge Sand) }\end{array}$ & $\begin{array}{c}\text { Júlio de } \\
\text { Magalhães } \\
\text { (Lisboa: Typ. da } \\
\text { Empreza Serões } \\
\text { Românticos) } \\
\end{array}$ & 1858 & Jornal do commercio & $\begin{array}{c}\text { (HEINEBERG, 2004b, } \\
\text { p. 63) }\end{array}$ & $\begin{array}{c}\text { L'homme de neige } \\
\text { (Revue des Deux Mondes, } \\
\text { 2e période, tome 15, } 1858 \\
\text { (pp. 481-522).) }\end{array}$ & 1859 \\
\hline 6. & $\begin{array}{l}\text { O Marquês de } \\
\text { Villemer }\end{array}$ & - & 1862 & Correio Mercantil & $\begin{array}{c}\text { (HEINEBERG, 2004b, } \\
\text { p. 63) }\end{array}$ & Le Marquis de Villemer & 1861 \\
\hline 7. & $\begin{array}{l}\text { Mademoiselle } \\
\text { Marquem }\end{array}$ & - & 1868 & $\begin{array}{l}\text { Diário do Rio de } \\
\text { Janeiro }\end{array}$ & $\begin{array}{c}\text { (HEINEBERG, 2004b, } \\
\text { p. 63) }\end{array}$ & Mademoiselle Merquem & 1868 \\
\hline 8. & Flamarande & - & $1875-1876$ & O Globo & $\begin{array}{c}\text { (SANTOS, 2009, p. } \\
\text { 139; SALVAIA, 2014, } \\
\text { p. 53) }\end{array}$ & Flamarande & 1875 \\
\hline 9. & Dois irmãos & - & 1876 & O Globo & $\begin{array}{c}\text { (SANTOS, 2009, p. } \\
\text { 139; SALVAIA, 2014, } \\
\text { p. 53) }\end{array}$ & Les Deux Frères & 1875 \\
\hline 10. & $\begin{array}{l}\text { O diabo no campo } \\
\text { - volume } 2\end{array}$ & Pedro dos Reys & 1888 & $\begin{array}{l}\text { Ed. David Corazzi } \\
\text { (Lisboa) }\end{array}$ & Livronauta & Le Diable au champs & 1856 \\
\hline
\end{tabular}


Tabela 2. Publicações de traduções da obra "Le Marquis de Villemer"

\begin{tabular}{|c|c|c|c|c|c|c|c|}
\hline & $\begin{array}{l}\text { Título da } \\
\text { tradução }\end{array}$ & Tradutor(a) & $\begin{array}{c}\text { Ano de } \\
\text { publicação }\end{array}$ & Editora & Fontes & $\begin{array}{l}\text { Título do } \\
\text { Original }\end{array}$ & $\begin{array}{c}\text { Ano de } \\
\text { Publicação }\end{array}$ \\
\hline 11. & $\begin{array}{l}\text { A dama de } \\
\text { companhia }\end{array}$ & - & - & $\begin{array}{c}\text { Casa } \\
\text { Mandarino } \\
\text { (RJ) }\end{array}$ & Livronauta $^{23}$ & $\begin{array}{c}\text { Le Marquis de } \\
\text { Villemer }\end{array}$ & 1861 \\
\hline 12. & $\begin{array}{l}\text { A dama de } \\
\text { companhia }\end{array}$ & - & - & $\begin{array}{l}\text { Ed. Getulio M. } \\
\text { Costa - Col.: } \\
\text { "Para Nossas } \\
\text { Filhas”. RJ, }\end{array}$ & (FERNANDES, 2012, p. 77) & $\begin{array}{c}\text { Le Marquis de } \\
\text { Villemer }\end{array}$ & 1861 \\
\hline 13. & $\begin{array}{l}\text { Ama de } \\
\text { companhia - o } \\
\text { Marquês de } \\
\text { Villemer }\end{array}$ & - & $\begin{array}{c}\text { 194? } \\
\text { (coleção } \\
\text { publicada na } \\
\text { década de } \\
\text { 1940) }\end{array}$ & $\begin{array}{l}\text { Editora } \\
\text { Aurora, } \\
\text { Coleção Azul } \\
\text { (livros de } \\
\text { bolso) }\end{array}$ & Estante Virtual & $\begin{array}{c}\text { Le Marquis de } \\
\text { Villemer }\end{array}$ & 1861 \\
\hline
\end{tabular}


Figura 1. Título original: Le Marquis de Villemer. Publicação: Editora Aurora. ${ }^{24}$

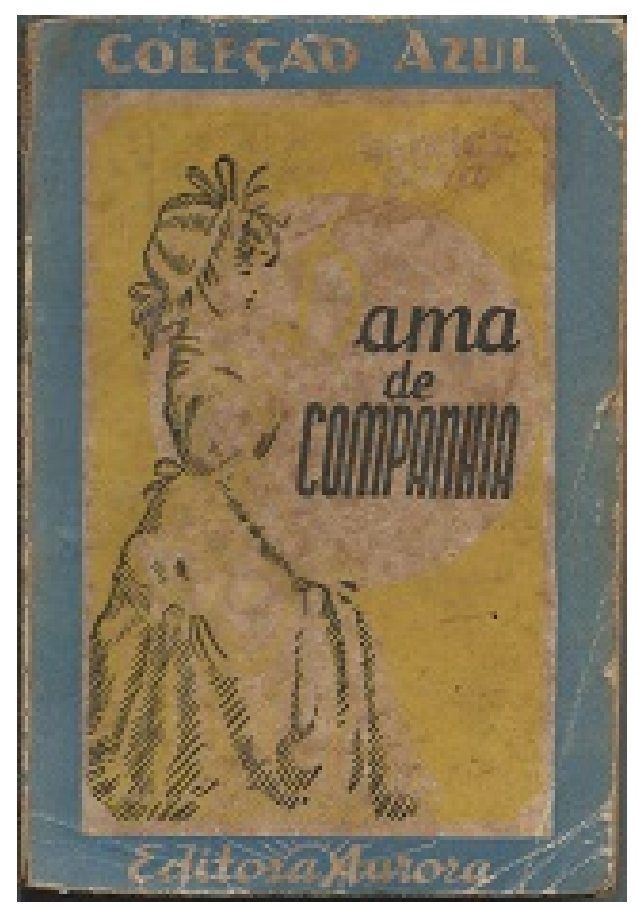


Tabela 3. Publicações de traduções da obra "La Petite Fadette"

\begin{tabular}{|r|c|c|c|c|c|c|c|}
\hline & Título da tradução & Tradutor(a) & $\begin{array}{c}\text { Ano de } \\
\text { publicação }\end{array}$ & Editora & Fontes & $\begin{array}{c}\text { Título do } \\
\text { Original }\end{array}$ & $\begin{array}{c}\text { Ano de } \\
\text { Publicação }\end{array}$ \\
\hline 14. & A pequena Fadette & $\begin{array}{c}\text { José Maria } \\
\text { Machado }\end{array}$ & - & $\begin{array}{c}\text { Edigraf (Coleção } \\
\text { Excelsior) }\end{array}$ & Sebo do Messias & La Petite Fadette & 1849 \\
\hline 15. & Os Gêmeos & Augusto Sousa & 1953 & $\begin{array}{c}\text { Editora Saraiva - } \\
\text { Col. "Saraiva" }\end{array}$ & (FERNANDES, 2012, p. 77) & La petite Fadette & 1849 \\
\hline 16. & A pequena Fadette & $\begin{array}{c}\text { José Maria } \\
\text { Machado }\end{array}$ & 1957 & Clube do Livro & (FERNANDES, 2012, p. 77) & La Petite Fadette & 1849 \\
\hline 17. & A pequena Fadette & - & 1972 & Abril Cultural & Skoob ${ }^{25}$ & La Petite Fadette & 1849 \\
\hline 18. & A pequena Fadette & $\begin{array}{c}\text { Jacqueline } \\
\text { Castro }\end{array}$ & 1973 & Abril Cultural & (FERNANDES, 2012, p. 77) & La Petite Fadette & 1849 \\
\hline 19. & A pequena Fadette & $\begin{array}{c}\text { Mônica Cristina } \\
\text { Corrêa }\end{array}$ & 2006 & Barcarolla & (FERNANDES, 2012, p. 77) & La Petite Fadette & 1849 \\
\hline
\end{tabular}


Figura 2. Título original: La petite Fadette. Capa da tradução de João Maria Machado. Publicação: Edigraf (Coleção Excelsior) ${ }^{\mathbf{2 6}}$

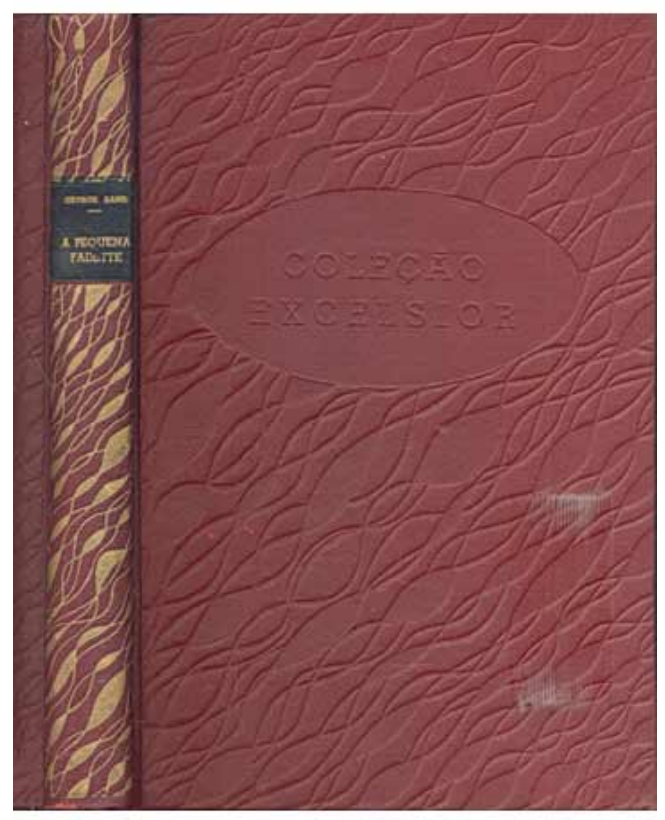

Figura 3. Título original: La petite Fadette. Folha de rosto da tradução de João Maria Machado. Publicação: Edigraf (Coleção Excelsior) ${ }^{27}$

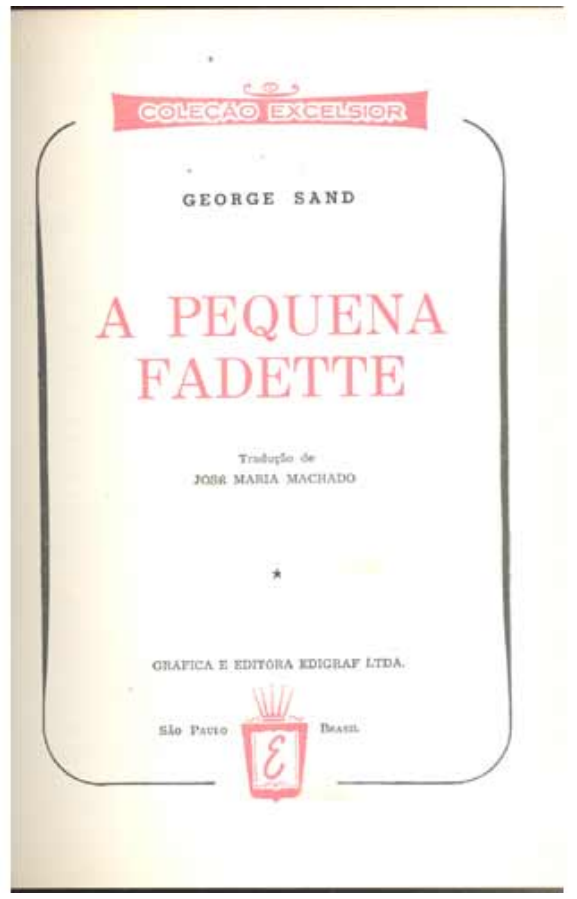


Figura 4. Título original: La petite Fadette. Tradução de Augusto Sousa. Publicação: Editora Saraiva, $1953 .^{28}$

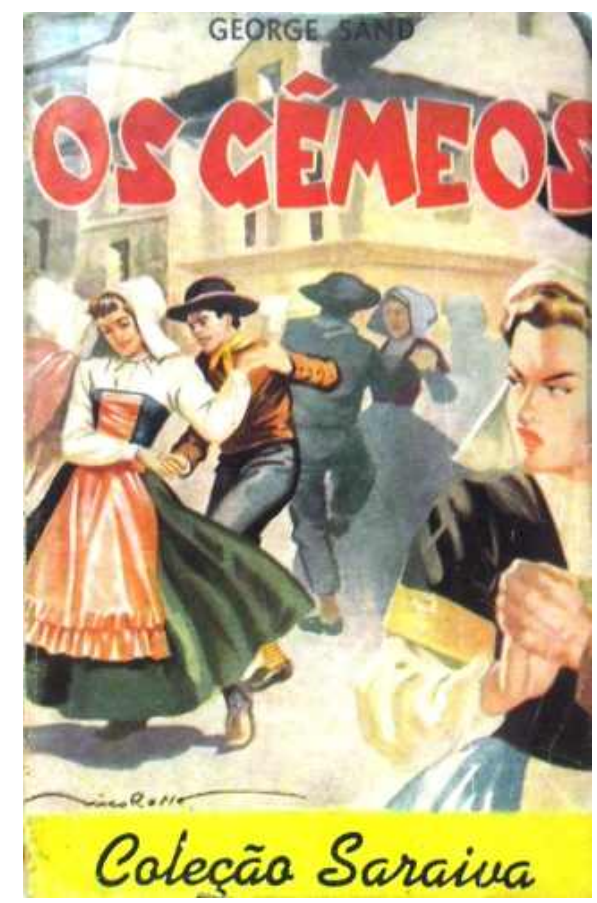

Figura 5. Título original: La petite Fadette. Capa da tradução de João Maria Machado. Publicação: Clube do Livro, $1957 .{ }^{29}$

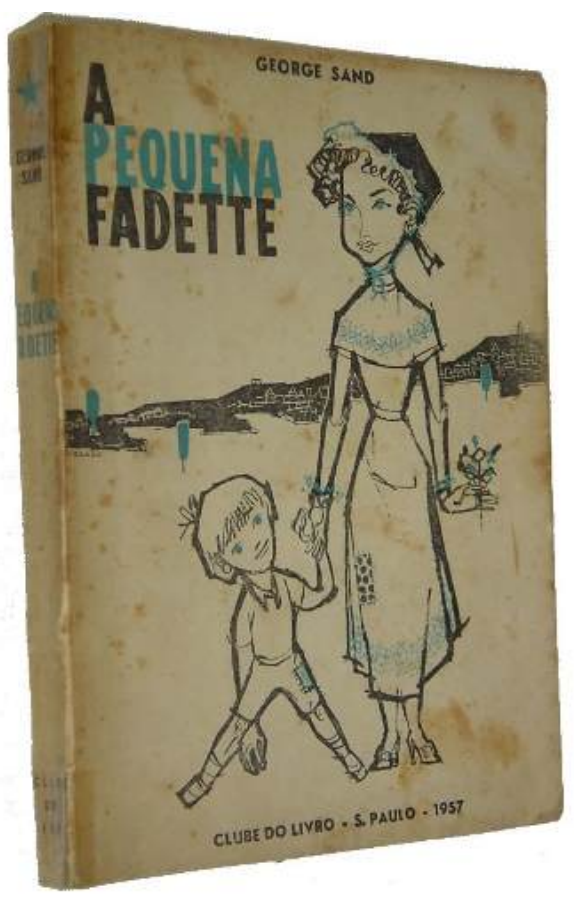


Figura 6. Título original: La petite Fadette. Capa da tradução de Jacqueline Castro. Publicação: editora Abril Cultural, 1973. ${ }^{30}$

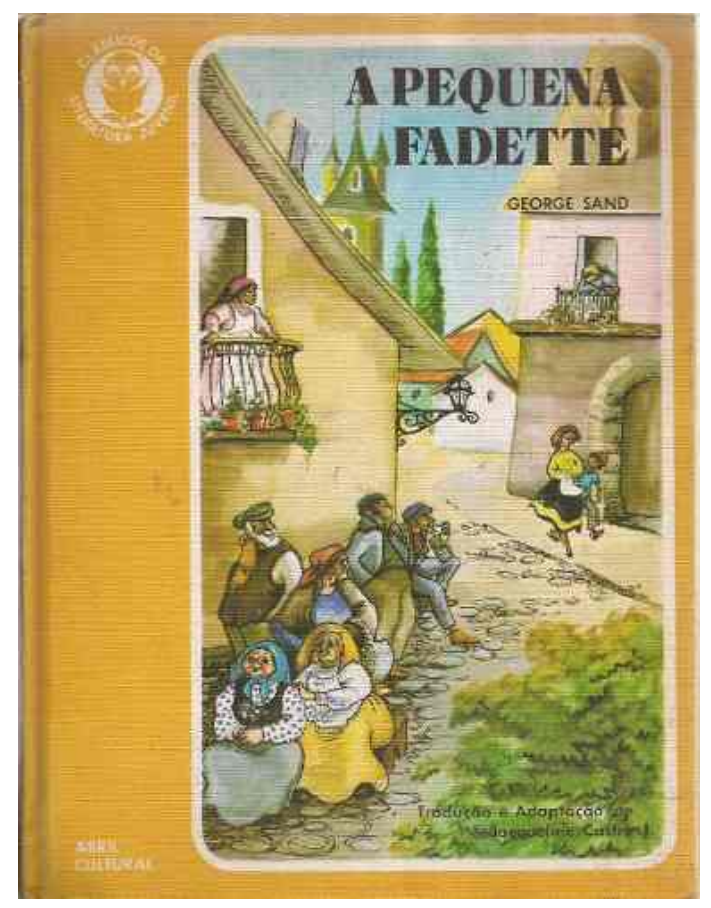

Figura 7. Título original: La petite Fadette. Capa da tradução de Mônica Cristina Monteiro. Publicação: editora Barcarolla, 2006. ${ }^{31}$

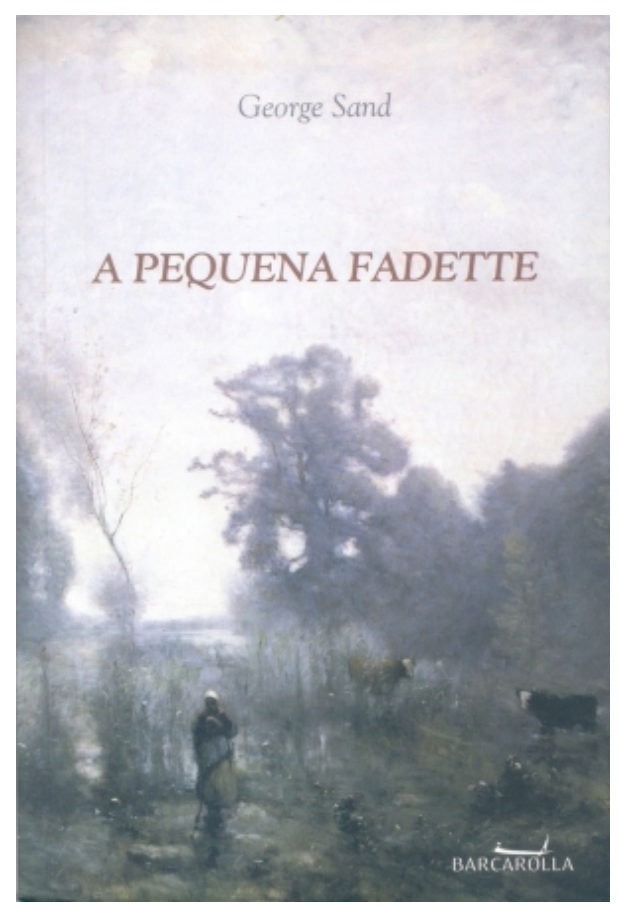


Tabela 4. Publicações de traduções da obra "Elle et Lui"

\begin{tabular}{|c|c|c|c|c|c|c|c|}
\hline & $\begin{array}{l}\text { Título da } \\
\text { tradução }\end{array}$ & Tradutor(a) & $\begin{array}{c}\text { Ano de } \\
\text { publicação }\end{array}$ & Editora & Fontes & $\begin{array}{c}\text { Título do } \\
\text { Original }\end{array}$ & $\begin{array}{c}\text { Ano de } \\
\text { Publicação }\end{array}$ \\
\hline 20. & Ela e ele & - & 1943 & $\begin{array}{c}\text { Editora } \\
\text { Vecchi - } \\
\text { Coleção } \\
\text { Coração em } \\
\text { Chamas }\end{array}$ & Museu de Arte Murilo Mendes ${ }^{32}$ & Elle et lui & 1859 \\
\hline 21. & Almas inquietas & $\begin{array}{c}\text { José Maria } \\
\text { Machado } \\
\text { Nota } \\
\text { explicativa: } \\
\text { Maria de } \\
\text { Lourdes } \\
\text { Teixeira }\end{array}$ & 1959 & $\begin{array}{l}\text { Clube do } \\
\text { Livro }\end{array}$ & (FERNANDES, 2012, p. 78) & Elle et lui & 1859 \\
\hline 22. & Ela e ele & $\begin{array}{c}\text { José Maria } \\
\text { Machado } \\
\text { Nota } \\
\text { Explicativa: } \\
\text { Evangelista } \\
\text { Prado }\end{array}$ & 1959 & $\begin{array}{l}\text { Clube do } \\
\text { Livro }\end{array}$ & (FERNANDES, 2012, p. 78) & Elle et lui & 1859 \\
\hline
\end{tabular}


Figura 8. Título original: Elle et lui. Tradução publicada pela Editora Vecchi - Coleção Coração em Chamas, $1946 .{ }^{33}$

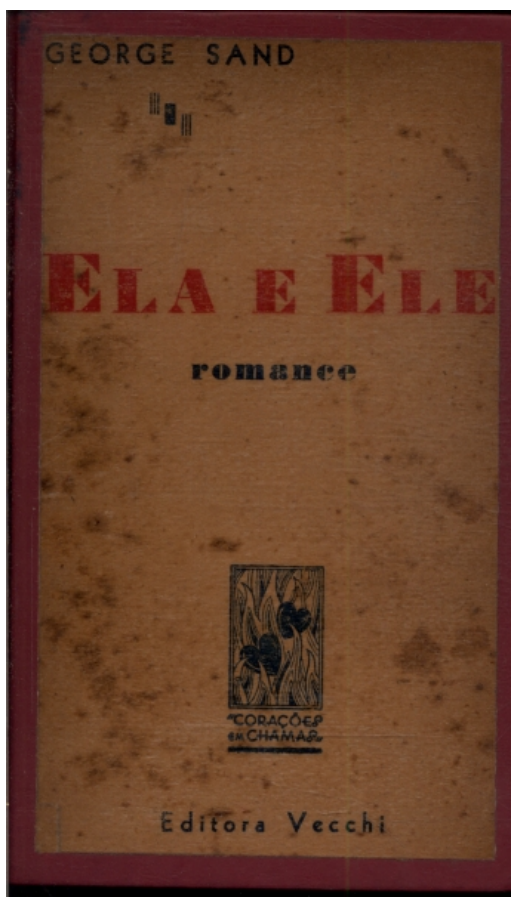

Figura 9. Título original: Elle et lui. Tradução de José Maria Machado. Publicação: Clube do Livro, $1959 .{ }^{34}$

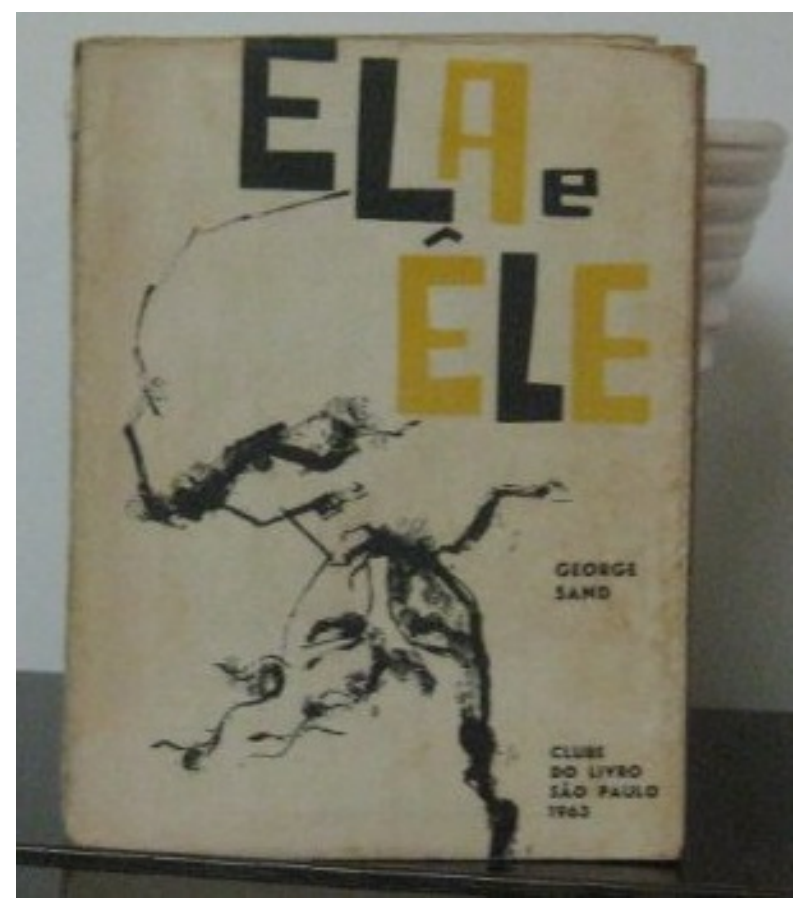


Figura 10. Título original: Elle et lui. Tradução de José Maria Machado. Publicação: Clube do Livro, $1959 .{ }^{35}$

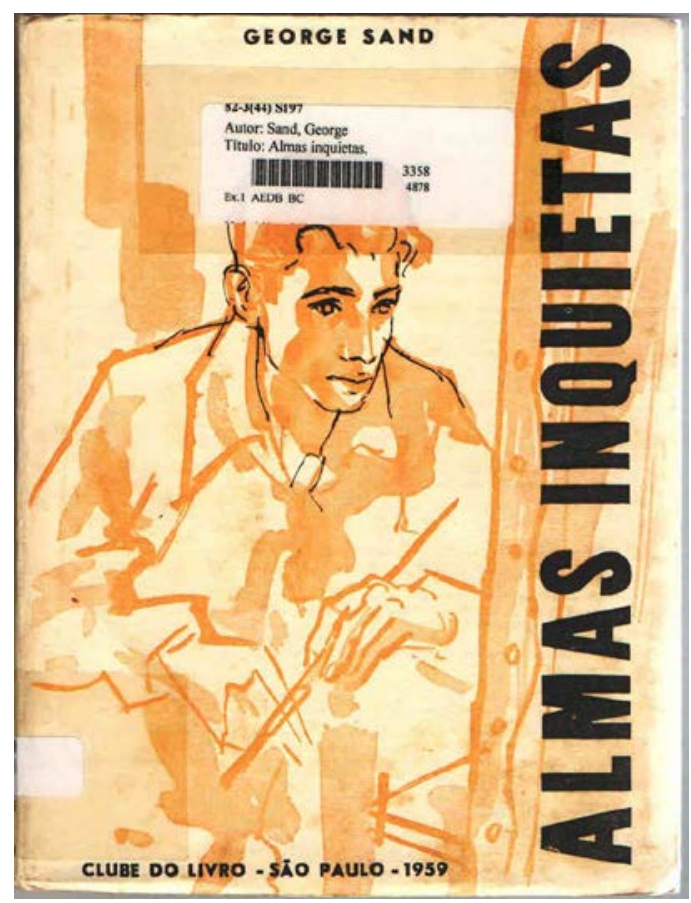


Tabela 5. Publicações de traduções da obra "Histoire de ma vie"

\begin{tabular}{|c|c|c|c|c|c|c|c|}
\hline & Título da tradução & Tradutor(a) & $\begin{array}{c}\text { Ano de } \\
\text { publicação }\end{array}$ & Editora & Fontes & $\begin{array}{l}\text { Título do } \\
\text { Original }\end{array}$ & $\begin{array}{c}\text { Ano de } \\
\text { Publicação }\end{array}$ \\
\hline 23. & $\begin{array}{l}\text { História da minha } \\
\text { vida (vol. 1) }\end{array}$ & $\begin{array}{c}\text { Gulnara Lobato de } \\
\text { Morais Pereira }\end{array}$ & \begin{tabular}{|c|}
$1^{\text {a }}$ edição: \\
1945; e $2^{\mathrm{a}}$. \\
edição: 1952$)$ \\
\end{tabular} & $\begin{array}{c}\text { José Olympio Editora - } \\
\text { Col. "Memórias, Diários, } \\
\text { Confissões" }\end{array}$ & (FERNANDES, 2012, p. 77) & $\begin{array}{c}\text { Histoire de ma } \\
\text { vie }\end{array}$ & 1854- 1855 \\
\hline 24. & $\begin{array}{l}\text { História da minha } \\
\text { vida (vol. 2) }\end{array}$ & $\begin{array}{c}\text { Gulnara Lobato de } \\
\text { Morais Pereira }\end{array}$ & 1945 & $\begin{array}{c}\text { José Olympio Editora - } \\
\text { Col. "Memórias, Diários, } \\
\text { Confissões" }\end{array}$ & (FERNANDES, 2012, p. 77) & $\begin{array}{c}\text { Histoire de ma } \\
\text { vie }\end{array}$ & 1854- 1855 \\
\hline 25. & $\begin{array}{l}\text { História da minha } \\
\text { vida (vol. 3) }\end{array}$ & $\begin{array}{c}\text { Gulnara Lobato de } \\
\text { Morais Pereira }\end{array}$ & 1946 & $\begin{array}{c}\text { José Olympio Editora - } \\
\text { Col. "Memórias, Diários, } \\
\text { Confissões" }\end{array}$ & (FERNANDES, 2012, p. 77) & $\begin{array}{c}\text { Histoire de ma } \\
\text { vie }\end{array}$ & 1854- 1855 \\
\hline 26. & $\begin{array}{l}\text { História da minha } \\
\text { vida (vol. 4) }\end{array}$ & $\begin{array}{c}\text { Gulnara Lobato de } \\
\text { Morais Pereira }\end{array}$ & 1946 & $\begin{array}{c}\text { José Olympio Editora - } \\
\text { Col. "Memórias, Diários, } \\
\text { Confissões" }\end{array}$ & (FERNANDES, 2012, p. 77) & $\begin{array}{l}\text { Histoire de ma } \\
\text { vie }\end{array}$ & 1854- 1855 \\
\hline 27. & $\begin{array}{l}\text { História da minha } \\
\text { vida (vol. 5) }\end{array}$ & $\begin{array}{c}\text { Gulnara Lobato de } \\
\text { Morais Pereira }\end{array}$ & 1947 & $\begin{array}{c}\text { José Olympio Editora - } \\
\text { Col. "Memórias, Diários, } \\
\text { Confissões" }\end{array}$ & (FERNANDES, 2012, p. 77) & $\begin{array}{c}\text { Histoire de ma } \\
\text { vie }\end{array}$ & 1854- 1855 \\
\hline
\end{tabular}


Tabela 6. Publicações de traduções de diversas obras de George Sand em meados do século XX

\begin{tabular}{|r|c|c|c|c|c|c|c|}
\hline & $\begin{array}{c}\text { Título da } \\
\text { tradução }\end{array}$ & Tradutor(a) & $\begin{array}{c}\text { Ano de } \\
\text { publicação }\end{array}$ & Editora & Fontes & $\begin{array}{c}\text { Título do } \\
\text { Original }\end{array}$ & $\begin{array}{c}\text { Ano de } \\
\text { Publicação }\end{array}$ \\
\hline 28. & Valentina & A. S. Costa & 1937 & Casa Mandarino & (FERNANDES, 2012, p. 77) & Valentine & 1832 \\
\hline 29. & Narciso & $\begin{array}{c}\text { Regina de } \\
\text { Carvalho }\end{array}$ & 1942 & $\begin{array}{c}\text { Ed. Anchieta Limitada - } \\
\text { Col. "Romance para } \\
\text { Moças" }\end{array}$ & (FERNANDES, 2012, p. 77) & Narcisse & 1859 \\
\hline 30. & Indiana & $\begin{array}{c}\text { Almir de } \\
\text { Andrade }\end{array}$ & 1943 & $\begin{array}{c}\text { Ed. José Olympio - } \\
\text { Coleção "Fogos } \\
\text { Cruzados" }\end{array}$ & (FERNANDES, 2012, p. 77) & Indiana & 1832 \\
\hline 31. & Jeanne & $\begin{array}{c}\text { Edith de } \\
\text { Carvalho Negrais }\end{array}$ & 1943 & $\begin{array}{c}\text { Ed. Anchieta Limitada - } \\
\text { Col. "Romance para } \\
\text { Moças" }\end{array}$ & (FERNANDES, 2012, p. 77) & Jeanne & 1844 \\
\hline 33. & Mauprat & $\begin{array}{c}\text { Almir de } \\
\text { Andrade }\end{array}$ & 1945 & $\begin{array}{c}\text { José Olympio - Col. } \\
\text { "Fogos Cruzados" }\end{array}$ & (FERNANDES, 2012, p. 77) & Mauprat & 1837 \\
\hline & O último amor & Alfredo Ferreira & 1952 & $\begin{array}{c}\text { Casa Editora Vecchi } \\
\text { LTDA. - Col. "Os mais } \\
\text { belos romances", Série } \\
\text { "Rubi" }\end{array}$ & (FERNANDES, 2012, p. 77) & $\begin{array}{c}\text { Le dernier } \\
\text { amour } \\
\text { (dedicado a } \\
\text { Gustav } \\
\text { Flaubert) }\end{array}$ & 1867 \\
\hline
\end{tabular}


Figura 11. Título original: Le dernier amour. Tradução de Alfredo Ferreira. Publicação: Casa Editora Vecchi LTDA. - Col. "Os mais belos romances", Série "Rubi", 1952. ${ }^{36}$

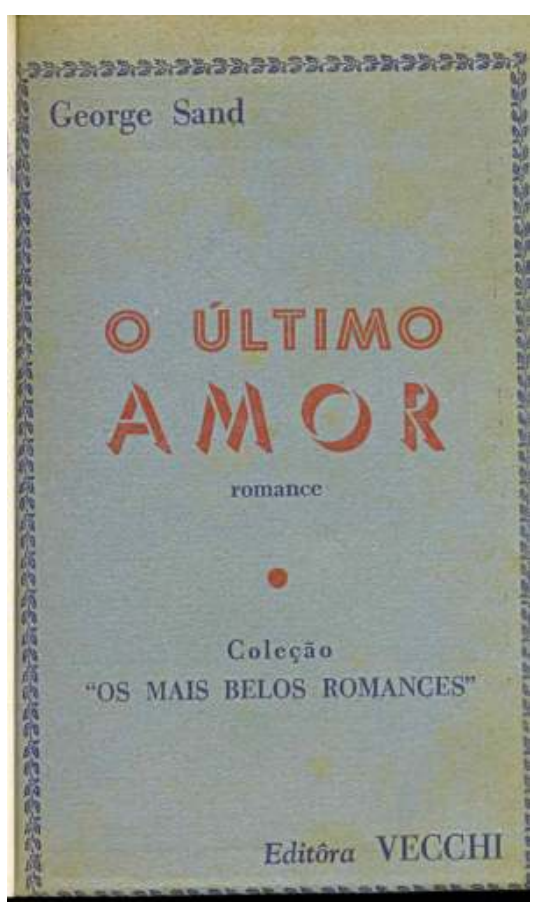


Tabela 7. Publicações de traduções da obra "La mare au Diable"

\begin{tabular}{|c|c|c|c|c|c|c|c|}
\hline & Título da tradução & Tradutor(a) & $\begin{array}{c}\text { Ano de } \\
\text { publicação }\end{array}$ & Editora & Fontes & $\begin{array}{l}\text { Título do } \\
\text { Original }\end{array}$ & $\begin{array}{c}\text { Ano de } \\
\text { Publicação }\end{array}$ \\
\hline 34. & O pântano do diabo & Adonias Filho & 1938 & & (MATTOS, 2011, p. 7) & $\begin{array}{c}\text { La Mare au } \\
\text { Diable }\end{array}$ & 1846 \\
\hline 35. & O charco do diabo & $\begin{array}{c}\text { José Maria } \\
\text { Machado }\end{array}$ & 1952 & $\begin{array}{l}\text { Clube do } \\
\text { Livro }\end{array}$ & (FERNANDES, 2012, p. 77) & $\begin{array}{c}\text { La Mare au } \\
\text { Diable }\end{array}$ & 1846 \\
\hline 36. & O pântano do diabo & $\begin{array}{l}\text { Maria Tostes } \\
\text { Regis }\end{array}$ & 1963 & $\begin{array}{l}\text { Editora Itatiaia } \\
\text { Limitada - } \\
\text { Col. } \\
\text { "Clássicos da } \\
\text { Juventude" }\end{array}$ & (FERNANDES, 2012, p. 77) & $\begin{array}{c}\text { La Mare au } \\
\text { Diable }\end{array}$ & 1846 \\
\hline
\end{tabular}


Figura 12. Título original: La mare au diable. Tradução de José Maria Machado. Publicação: Clube do Livro, 1952. ${ }^{37}$

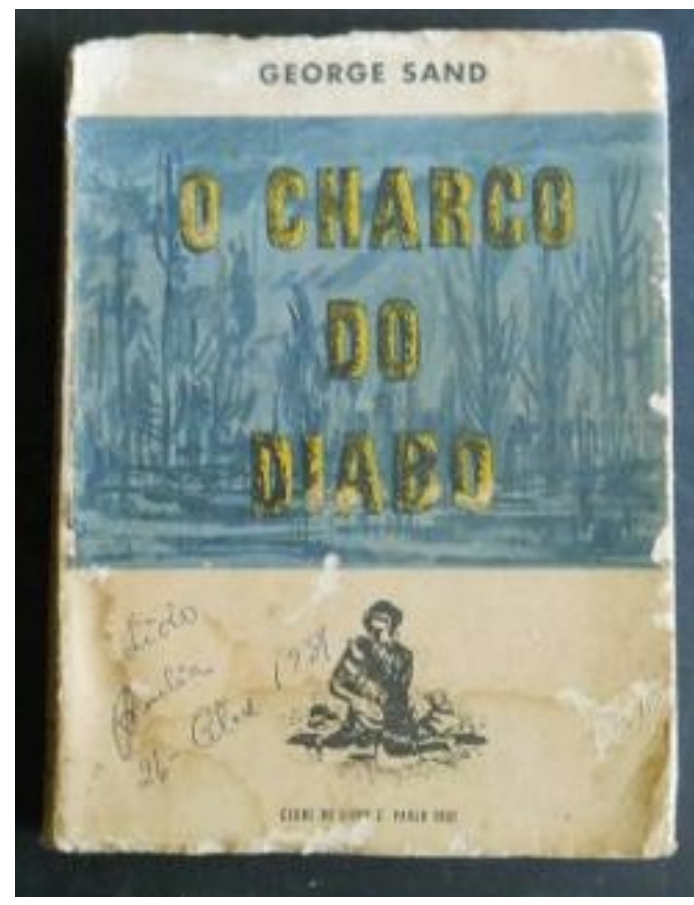

Figura 13. Título original: La mare au diable, folha de rosto. Tradução de José Maria Machado. Publicação: Clube do Livro, 1952.

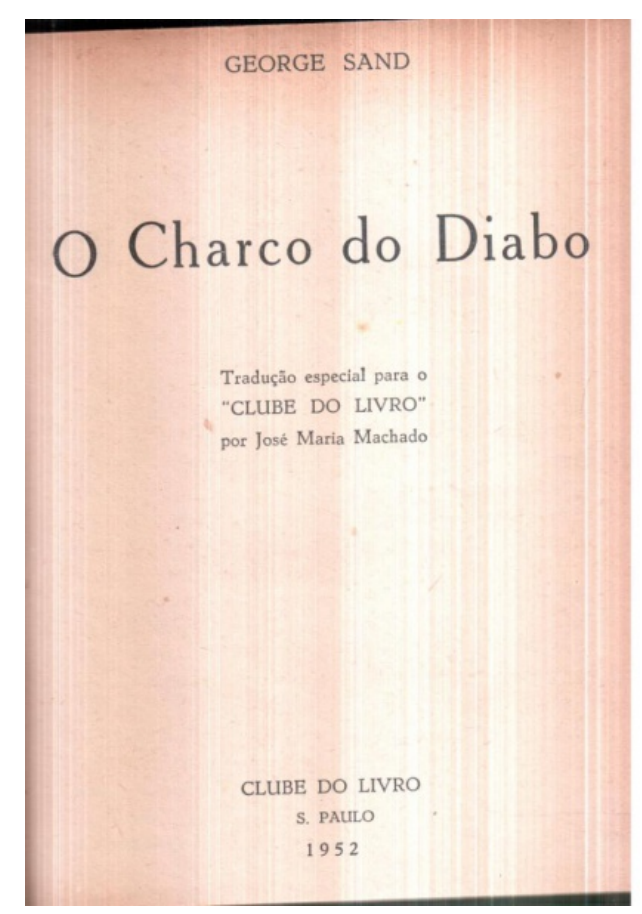


Figura 14. Título original: La mare au diable. Tradução: Maria Tostes Regis. Publicação: Editora Itatiaia Ltda., Coleção “Clássicos da Juventude”, 1963. ${ }^{38}$

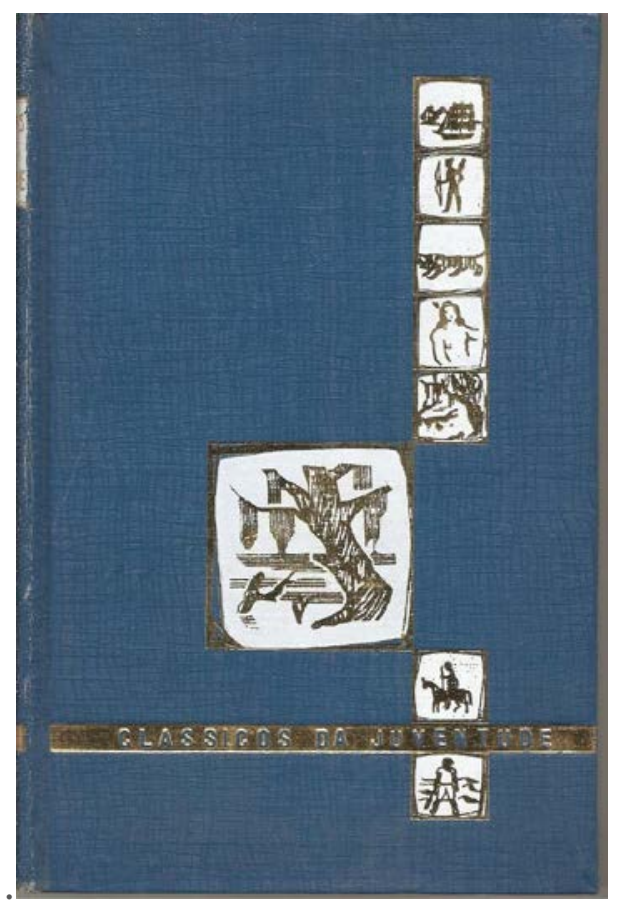

Figura 2. Título original: La mare au diable, folha de rosto. Tradução: Maria Tostes Regis. Publicação: Editora Itatiaia Ltda., Coleção “Clássicos da Juventude”, 1963. ${ }^{39}$

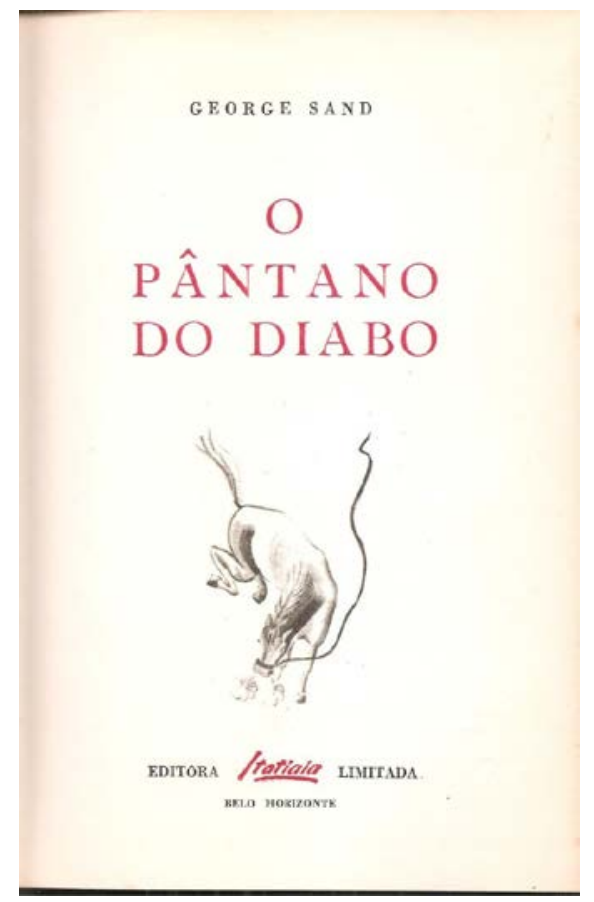


Figura 16. Título original: La mare au diable. Tradução: Maria Tostes Regis. Publicação: Editora Itatiaia Ltda., Coleção “Clássicos da Juventude”, 1963. ${ }^{40}$

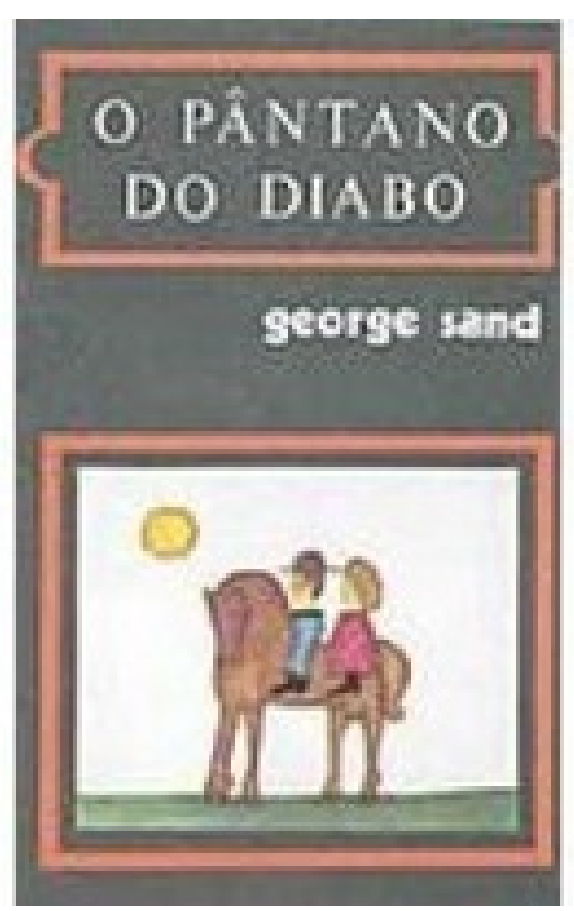


Tabela 8. Publicações de traduções de obras de George Sand no século XXI

\begin{tabular}{|c|c|c|c|c|c|c|c|}
\hline & Título da tradução & Tradutor(a) & $\begin{array}{c}\text { Ano de } \\
\text { publicação }\end{array}$ & Editora & Fontes & $\begin{array}{l}\text { Título do } \\
\text { Original } \\
\end{array}$ & $\begin{array}{c}\text { Ano de } \\
\text { Publicação }\end{array}$ \\
\hline 37. & Espiridião & Milton Hatoum & 2005 & $\begin{array}{l}\text { Companhia das Letras. } \\
\text { IN: MANGEL, Alberto } \\
\text { (Org.e Introdução) } \\
\text { Contos de horror do } \\
\text { século XIX. SP, } \\
\text { Companhia das Letras, } \\
\text { pp. 344- } \\
352 \\
\end{array}$ & $\begin{array}{l}\text { (FERNANDES, 2012, p. } \\
\text { 77) }\end{array}$ & Spiridion & 1839 \\
\hline 38. & $\begin{array}{l}\text { História do verdadeiro } \\
\text { Simplício }\end{array}$ & $\begin{array}{l}\text { Cláudio } \\
\text { Giordano }\end{array}$ & 2013 & $\begin{array}{c}\text { Ed. SESI-SP - } \\
\text { Coleção: Quem lê Sabe } \\
\text { Por quê }\end{array}$ & $\begin{array}{l}\text { Livraria SESI-SP, } \\
\text { SENAI-SP. }\end{array}$ & $\begin{array}{l}\text { Histoire du } \\
\text { véritable } \\
\text { Gribouille }\end{array}$ & 1850 \\
\hline 39. & O carvalho falante & $\begin{array}{l}\text { Dorothée de } \\
\text { Bruchard }\end{array}$ & 2013 & Autentica & Grupo Autêntica & $\begin{array}{c}\text { Le chêne } \\
\text { parlant - } \\
\text { IN : Contes } \\
\text { d'une Grand- } \\
\text { mère (tome I) }\end{array}$ & $1873-1876$ \\
\hline
\end{tabular}


Figura 17. Contos de Horror do século XIX. Contém a tradução de Spiridion. Tradução de Milton Hatoum. Publicação: Companhia das Letras, 2005. ${ }^{41}$

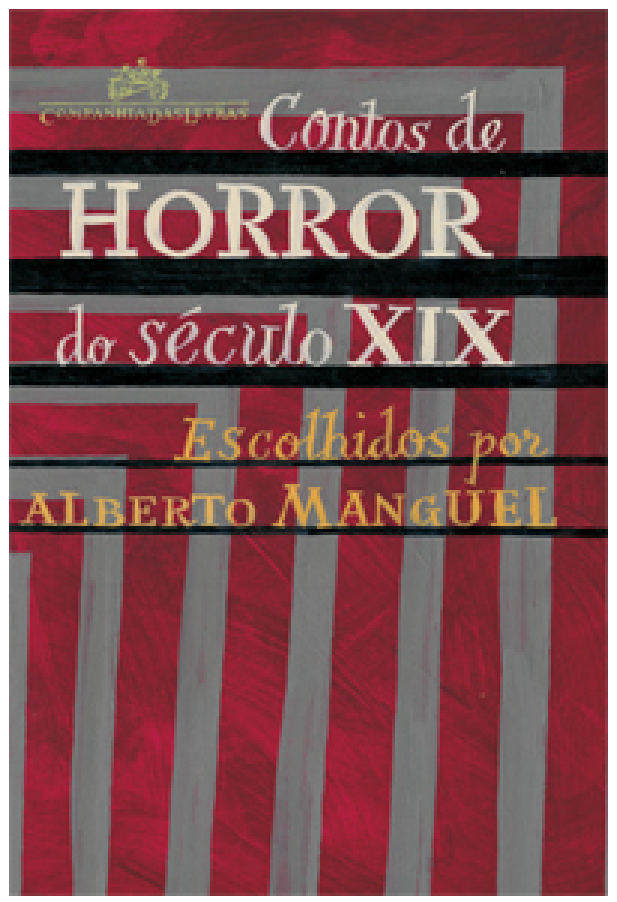

Figura 18. Texto original: Histoire du véritable Gribouille. Tradução de Cláudio Giordano. Publicação: Editora Sesi-SP, 2013. ${ }^{42}$

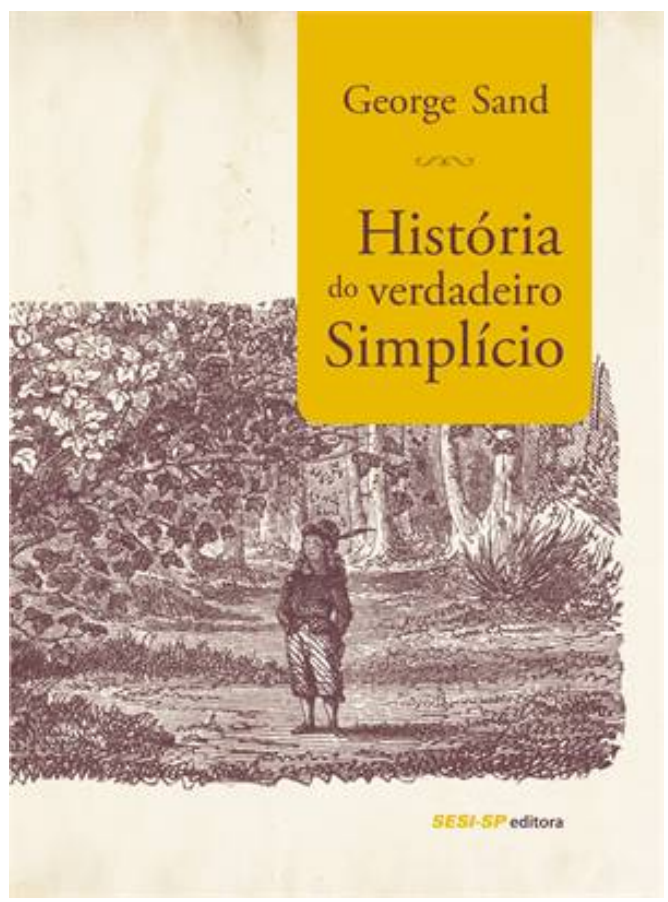


Figura 19. Texto original: Le chêne parlant (Contes d'une Grand-mère). Tradução de Dorothée de Bruchard. Publicação: editora Autentica, 2013. ${ }^{43}$

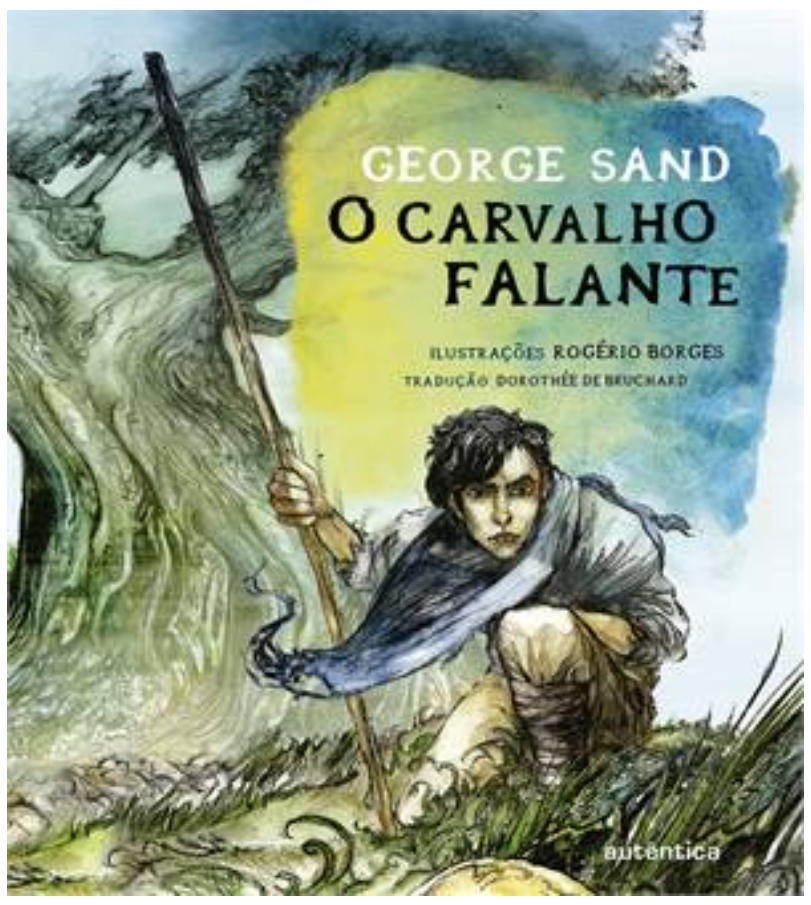




\section{REFERÊNCIAS BIBLIOGRÁFICAS}

CANDIDO, Antonio. Formação da literatura brasileira. Belo Horizonte: Itatiaia, 2000.

COBELO, Silvia. Os tradutores do Quixote publicados no Brasil. Rio de Janeiro: Tradução em Revista, 2010, p. 1 - 36. Disponível em: http://www.maxwell.vrac.pucrio.br/16557/16557.PDFXXvmi=ZL1GPx4KbckVZaz2Q2Sc9aRuZ380iiWi4ZZUw4GIh1Egc ei4gcgqm9Wlc5mvnkOsjOnQS4Aa6fritLmLxEckN9H1e5wDpl6KatC4zceFrHZWsmIq2UM P5uRjAox0L4KVzm18AgO3xN0qbISdEG4JbV4Ml2M76x4FV5OvlDzjrALDiFQWmUGzR LldN9IUIpAEupbQ3Lbulx9FD0C0VjAO6V3T5oONOpsjQFbTqnpNlzs0A61wqBlwxorDNh rDHUWx. Acesso: abril 2015.

ESTEVES, João; CASTRO, Zília Osório de. Feminae Dicionário Contemporâneo. Lisboa, Portugal: Comissão para a cidadania e a igualdade de gênero, 2013, 930p. Disponível em: http://cid.cig.gov.pt/Nyron/Library/Catalog/winlibimg.aspx?skey=29B2B35459D64C98A339 6F5C0ADF2215\&doc=95065\&img=139416. Acesso: jun. 2015.

FERNANDES, Magali Oliveira. Éditions de George Sand au Brésil. IN: Femme et littérature populaire. Edicions de la Universitat de Lleida, 2012, p. 270p. ISBN10: 8484095746. Disponível

em: http://www.raco.cat/index.php/UllCritic/article/viewFile/267241/354816. Acesso: março 2015.

. O Processo Criativo no Universo da Edição - George Sand no Brasil. São Paulo: Revista Tessituras \& Criação, Número 3, 2012, p. 64 - 84. Disponível em: http://revistas.pucsp.br/index.php/tessituras/article/view/11406/8313. Acesso: março 2015.

George Sand 1804 - 1876. Disponível em: http://www.georgesand.culture.fr/ Acesso: abril 2015.

GUIMARÃES, Rosângela Maria Oliveira. Traduções/Adaptações dos Romances-folhetins de Alexandre Dumas no Brasil: Estudos de Edição e Cultura. (Tese de Doutorado). São Paulo: Pontifícia Universidade Católica de São Paulo, 2008, 249p. Disponível em: http://www.sapientia.pucsp.br/tde_arquivos/1/TDE-2008-04-10T10:22:17Z-

5198/Publico/Rosangela\%20Maria\%20Oliveira\%20Guimaraes.pdf. Acesso: abril, 2015.

HEINEBERG, Ilana. La suíte au prochain numéro : Formation du roman-feuilleton brésilien à partir des quotidiens Jornal do commercio, Diário do Rio de Janeiro et Correio mercantil (1839-1870). Volume 1. (Tese de doutorado - Études Lusophones / Littérature Brésilienne). Paris, França: Université de la Sorbonne Nouvelle - Paris III, 2004a, 397p.

. La suíte au prochain numéro : Formation du roman-feuilleton brésilien à partir des quotidiens Jornal do commercio, Diário do Rio de Janeiro et Correio mercantil (18391870). Volume 2. (Tese de doutorado - Études Lusophones / Littérature Brésilienne). Paris, França: Université de la Sorbonne Nouvelle - Paris III, 2004b, 284p.

IPPOLITO, Christophe. La conclusion d'Indiana. Revue d'histoire littéraire de la France, 2009, vo. 109. Disponível em: http://www.cairn.info/zen.php?ID_ARTICLE=RHLF_093_0555\#. Acesso: abril 2015. 
MACIEL, Anamelia Dantas. AUTOBIOGRAFIA E MEMÓRIA: uma comparação entre as obras Histoire de ma Vie e Voltar a Palermo. (Tese de doutorado em Teoria Literária) Recife: Universidade Federal de Pernambuco, 2011, 196p.

MATTOS, Cyro. Histórias dispersas de Adonias Filho. Ilheus: Editus, 2011, 150p. Disponível em: http://www.uesc.br/editora/livrosdigitais2015/historias_adonias_filho.pdf. Acesso: maio 2015.

MÜLLER , Andréa Correa Paraíso. A ficção francesa e a consolidação do romance no Brasil. In: IX Seminário Internacional de História da Literatura, 2011, Porto Alegre. Anais. Porto Alegre-RS: Edipucrs, 2011, p. 63 - $73 . \quad$ Disponível em: http://ebooks.pucrs.br/edipucrs/Ebooks/Web/978-85-397-0198-8/Trabalhos/7.pdf. Acesso: jun. 2015.

OUTEIRINHO, Maria de Fátima. Mulheres oitocentistas: George Sand vista por Maria Amália Vaz de Carvalho. Disponível em: http://repositorioaberto.up.pt/bitstream/10216/8711/2/4394.pdf.

RAFAEL, Gina Guedes. Jornais, romance-folhetim e a literatura feminina no século XIX: influências transatlânticas? Recife: Revista IRIS, 2012, v.1, n.1, p. 32 - 42. Disponível em: http://www.repositorios.ufpe.br/revistas/index.php/IRIS/article/download/9/7.

SALVAIA, Priscila. Diálogos possíveis: o folhetim Helena (1876), de Machado de Assis, no $O$ Globo. (Dissertação de Mestrado). Campinas: Universidade de Campinas, 2014, 166p. Disponível em: http://www.bibliotecadigital.unicamp.br/document/?code=000931456.

SANTOS, Rogério Fernandes dos Santos. O Reflexo de Helena - modelos literários e nacionalidade em Helena (1876), de Machado de Assis. (Dissertação de Mestrado). São Paulo: Universidade de São Paulo, 2009, 147p.

\footnotetext{
${ }^{1}$ Lattes Patrícia Rodrigues Costa. Disponível em: http://lattes.cnpq.br/9546437584230118

${ }^{2}$ Lattes Germana Henriques Pereira de Sousa. Disponível em: lattes.cnpq.br/5479032498605468

${ }^{3}$ Casimir Dudevant. Disponível em: http://www.georgesand.culture.fr/fr/ent/en_fa_casimir_dudevant.htm
}

4 Stéphane Ajasson de Grandsagne. Disponível em:
http://www.georgesand.culture.fr/fr/ent/en_am_ajasson_grandsagne.htm

5 LAROUSSE. George Sand née Aurore Dupin baronne Dudevant. Disponível em: http://www.larousse.fr/encyclopedie/personnage/Aurore_Dupin_baronne_Dudevant_dite_George_Sand/143001

${ }^{6}$ Jules Sandeau. Disponível em: http://www.georgesand.culture.fr/fr/ent/en_am_jules_sandeau.htm

7 George Sand $1804 \quad$ - $\quad 1876 . \quad$ Marie Dorval. Disponível em : http://www.georgesand.culture.fr/fr/ent/en_th_marie_dorval.htm. Acesso: jun. 2015.

8 LAROUSSE. George Sand née Aurore Dupin baronne Dudevant. Disponível em : http://www.larousse.fr/encyclopedie/personnage/Aurore_Dupin_baronne_Dudevant_dite_George_Sand/143001. Acesso: jun. 2015.

${ }^{9}$ La passion Musset. Disponível em: http://www.georgesand.culture.fr/fr/am/am03.htm

${ }^{10}$ Les années Chopin. Disponível em: http://www.georgesand.culture.fr/fr/am/am06.htm 
${ }^{11}$ Alexandre Manceau. Disponível em: http://www.georgesand.culture.fr/fr/am/am10.htm

12 PORBASE - Base Nacional de Dados Bibliográficos. Disponível em: http://porbase.bnportugal.pt/ipac20/ipac.jsp?session=1C3810T321940.1368147\&menu=search\&aspect=subtab1 $5 \&$ npp $=20 \&$ ipp $=20 \&$ spp $=20 \&$ profile $=$ porbase $\& \mathrm{ri}=\&$ index $=$. AW\&term $=$ SAND $\% 2 C+$ George \&oper $=$ and $\& x=10$ $\& y=6 \&$ aspect=subtab15\&index $=$. TW\&term $=\&$ oper $=$ and\&index $=. A W \&$ term $=\& o p e r=$ and \&index $=$. SW \&term $=$ \&limitbox_1=\&limitbox_2=\&limitbox_3=\&limitbox_4=\&limitbox_5=LNG01+\%3D+por\&limitbox_6=PAI01+ $\% 3 \mathrm{D}+\mathrm{PT} \& u l t y p e=\& u l o p e r=\% 3 \mathrm{D} \& u$ llimit $=$ \&ultype $=$ \&uloper $=\% 3 \mathrm{D} \&$ ullimit $=\&$ sort $=3100012 . \quad$ Acesso: $\quad$ jun. 2015.

13 O Marquês de Villemer/George Sand. Disponível em : http://catalogo.bnportugal.pt/ipac20/ipac.jsp?session=14F81465N6L39.20394\&profile=bn\&source= !bnp\&view =subscriptionsummary\&uri=full=3100024 $! 358427 \sim$ !9\&ri=2\&aspect=subtab15\&menu=search\&ipp=20\&spp=2 $0 \&$ staffonly $=\&$ term $=$ George + sand\&index $=. A W \& u i n d e x=\&$ aspect $=$ subtab $15 \&$ menu $=$ search $\& \mathrm{ri}=2$

${ }^{14}$ Jules Sandeau. George Sand 1804 - 1876. Disponível em: http://www.georgesand.culture.fr/fr/am/am02.htm. Acesso: abril 2015.

15 Catálogo de autores - Biblioteca Marlene de Oliveira Alvarenga. Disponível em: http://www.gleg.com.br/CATALOGODEAUTORES.pdf

16 BOTTMANN, Denise. As traduções especiais do Clube do Livro II. Disponível em: http://naogostodeplagio.blogspot.com.br/2011/11/as-traducoes-especiais-do-clube-do_06.html.

17 BOTTMANN, Denise. José Maria Machado “tradutor”. Disponível em: http://naogostodeplagio.blogspot.com.br/2014/11/jose-maria-machado-tradutor.html.

18 Disponível em: http://www.abebooks.co.uk/book-search/title/les-jumeaux/author/sand-george-harding-katemary/

${ }^{19}$ Agradecemos ao bibliotecário Marcos Santos da Associação Educacional Dom Bosco, bem como à instituição, pelo auxílio à essa pesquisa, por meio de e-mail trocado em 29 de abril de 2015.

20

Disponível

em:

http://aleph20.letras.up.pt/F/6D3LIFGXS5YVYIU4KXFGID5DUMRCL6UQ249VFAP9BNS41HD1B1-

34756 ? func $=$ find -

b\&amp $=\& a m p=\& a m p=\&$ request $=000112758 \&$ find_code $=$ SYS\&local_base $=F L P 01 \& p d s \_h a n d l e=G U E S T$

${ }^{21}$ Disponível em: http://www.georgesand.culture.fr/fr/ec/ec16.htm

${ }^{22}$ Disponível em: http://www.georgesand.culture.fr/fr/ec/ec19.htm\#

${ }^{23}$ Disponível em: http://www.livronauta.com.br/livro-George_Sand-A_Dama_de_Companhia-Casa_MandarinoBalaio_Digital-Porto_Alegre-47805537

${ }^{24}$ Disponível em: http://www.estantevirtual.com.br/bybliophylia/George-Sand-Ama-de-Companhia-o-Marquesde-Villemer-106278286

${ }^{25}$ Disponível em: http://www.skoob.com.br/a-pequena-fadette-22236ed24113.html

${ }^{26}$ Disponível em: https://sebodomessias.com.br/livro/literatura-estrangeira/a-pequena-fadette-6.aspx

${ }^{27}$ Disponível em: https://sebodomessias.com.br/livro/literatura-estrangeira/a-pequena-fadette-6.aspx

${ }^{28}$ Disponível em: http://www.brechofuzenga.com/product/902084/livro-os-gemeos-george-sand

29 Disponível em: http://produto.mercadolivre.com.br/MLB-641972472-a-pequena-fadette-george-sand-1957livro-_JM

$30 \quad$ Disponível em: http://www.lufernandes.com.br/2010/wp-content/gallery/editorabarcarolla/a_pequena_fadette.jpg

${ }^{31}$ Disponível em:

barcarolla/a_pequena_fadette.jpg

${ }^{32}$ Disponível em: http://www.museudeartemurilomendes.com.br/arquivos/alencar310113.pdf

${ }^{33}$ Disponível em: http://www.traca.com.br/livro/715489/ 
$34 \quad$ Disponível em: http://produto.mercadolivre.com.br/MLB-652953261-ela-e-ele-george-sand_JM\#redirectedFromParent

35 Imagem recebida por e-mail em 29 de abril de 2015 por biblioteca@aedb.br.

${ }^{36}$ Disponível em: http://www.traca.com.br/livro/344107/o-ltimo-amor

${ }^{37}$ Disponível em: http://www.estantevirtual.com.br/rodrigo1312/George-Snad-O-Charco-do-Diabo-111751072

38 Disponível em: http://produto.mercadolivre.com.br/MLB-639870449-classicos-da-juventude-o-pntano-dodiabo-1963-_JM\#redirectedFromParent

39 Disponível em: http://produto.mercadolivre.com.br/MLB-639870449-classicos-da-juventude-o-pntano-dodiabo-1963-_JM\#redirectedFromParent

${ }^{40}$ Disponível em: http://www.skoob.com.br/livro/resenhas/126683/recentes/

${ }^{41}$ Disponível em: http://www.companhiadasletras.com.br/detalhe.php?codigo=12001

$288 \quad{ }^{42}$ Disponível em: http://www.livrariasesisenaisp.com.br/historia-do-verdadeiro-simplicio-657463-p201829

${ }^{43}$ Disponível em: http://grupoautentica.com.br/autentica-infantil-e-juvenil/livros/o-carvalho-falante/1019

RECEBIDO EM: 10 de junho de 2015

ACEITO EM: 30 de junho de 2015 